\title{
Colonic anisakiasis
}

\section{Nicola Mumoli MD, Andrea Merlo MD}

A 56-year-old man presented with a 1month history of nausea and colicky pain in the lower left quadrant of his abdomen. He had no fever, sweating or constipation. His medical history was unremarkable. On further questioning, the patient reported having eaten sushi and sashimi at a restaurant a month before his symptoms began. He had mild tenderness in the lower left quadrant of the abdomen. He had no signs of hypersensitivity, such as urticaria or angioedema. His leukocyte count was elevated, without eosinophilia. Stool samples were negative for occult blood. Findings on plain radiography and ultrasonography of the abdomen were unremarkable. On colonoscopy, a large fungating-type submucosal polyp of the descending colon was found. Unexpectedly, biopsy of the lesion brought out a live worm (Anisakis simplex, Figure 1), which was successfully removed (see Appendix 1 for a video of the procedure, available at www.cmaj.ca/lookup /suppl/doi:10.1503/cmaj.120909/-/DC1). Histopathologic examination of the biopsy specimen showed granuloma formation with edema and inflammatory infiltrate of eosinophils and lymphocytes in the submucosa of the intestinal wall.

Anisakiasis is a parasitic disease of the gastrointestinal tract caused by nematodes (roundworms) belonging to the Anisakidae family. The life cycle of anisakids is described in Appendix 2 (available at www.cmaj.ca/lookup /suppl/doi:10.1503/cmaj.120909/-/DC1). Humans become incidental hosts after eating raw, smoked or undercooked seafood and fish containing larvae. ${ }^{1,2}$ In North America, infections are often related to ingestion of Atlantic or Pacific cod, salmon, Pacific halibut and red snapper. In Japan and Europe, the risk is increased with ingestion of sardines, anchovies, tuna, mackerel and squid. ${ }^{2}$

Clinical syndromes associated with anisakid infection are gastric, intestinal and allergic. ${ }^{2}$ Gastric anisakiasis is characterized by the abrupt onset (generally 1-12 hours after ingestion of

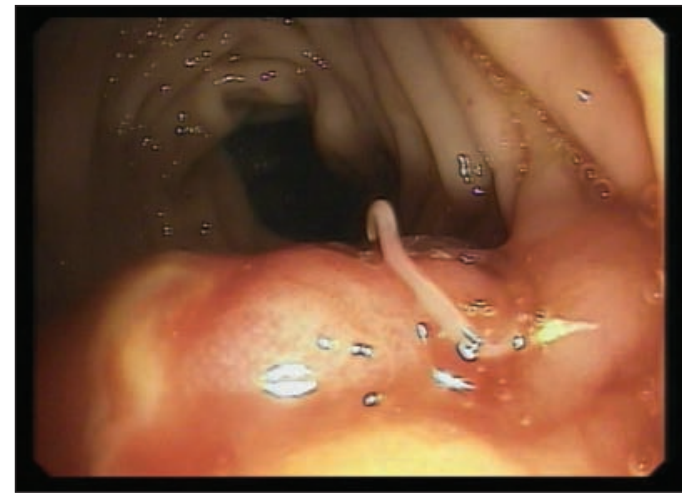

Figure 1: A live worm (Anisakis simplex) found on biopsy of a large fungating-type submucosal polyp in the descending colon of a 56-year-old man with abdominal pain and nausea.

infected fish or seafood) of severe epigastric pain, nausea and vomiting. Colonic anisakiasis is relatively rare, and diagnosis is often difficult because of the nonspecificity of the symptoms. In chronic infections, symptoms of intermittent malaise and abdominal pain may be misdiagnosed. ${ }^{3}$ Finally, allergic symptoms range from urticaria and isolated angioedema to anaphylaxis.

No medical therapy has been shown to be beneficial. ${ }^{2}$ Endoscopic removal of the nematode is the only effective treatment and is the only method to confirm the diagnosis. ${ }^{2}$

\section{References}

1. Sakanari JA, McKerrow JH. Anisakiasis. Clin Microbiol Rev 1989;2:278-84.

2. Hochberg NS, Hamer DH. Anisakidosis: perils of the deep. Clin Infect Dis 2010;51:806-12.

3. Mineta S, Shimanuki K, Sugiura A, et al. Chronic anisakiasis of the ascending colon associated with carcinoma. J Nippon Med Sch 2006;73:169-74
Competing interests: None declared.

This article has been peer reviewed.

Affiliation: Department of Internal Medicine, Ospedale Civile Livorno, Livorno, Italy

Acknowledgement: The authors acknowledge Dr. Josè Vitale for his expertise in this case.

Correspondence to: Nicola Mumoli, nimumoli@tiscali.it

CMAJ 2013. DOI:10.1503 /cmaj.120909
Please see the following video online at www.cmaj.ca/lookup/suppl /doi:10.1503/cmaj.120909/-/DC1: A live worm (Anisakis simplex) found on biopsy of a large fungating-type submucosal polyp in the descending colon of a 56-year-old man with abdominal pain and nausea. 